\title{
Laboratory-confirmed COVID-19 in children and youth in Canada, January 15-April 27, 2020
}

\author{
Dana Paquette ${ }^{1}$, Christopher Bell ${ }^{1}$, Maxime Roy ${ }^{1}$, Lindsay Whitmore ${ }^{1 *}$, Andrea Currie ${ }^{1}$, \\ Chris Archibald ${ }^{1}$, Diane MacDonald ${ }^{1}$, Jennifer Pennock ${ }^{1}$
}

\begin{abstract}
Understanding the epidemiology of COVID-19 among children and youth in Canada will help to inform public health measures in settings where children gather. As of April 27, 2020, provinces and territories provided the Public Health Agency of Canada with detailed information on 24,079 cases, of which $3.9 \%(n=938)$ were younger than 20 years of age. The detection rate per 100,000 population was lower in this age group $(11.9$ per 100,000$)$, compared with those aged $20-59$ years $(72.4$ per 100,000$)$ and 60 and older $(113.6$ per 100,000$)$. The median age among those younger than 20 years of age was 13 years, and cases were distributed equally across male and female genders. Among provinces and territories with more than 100 cases, $1.6 \%$ to $9.8 \%$ of cases were younger than 20 years of age. Cases in this age group were more likely to be asymptomatic: $10.7 \%$ compared with $2.4 \%$ in those aged $20-59$ years and $4.1 \%$ in those aged 60 and older. Children and youth experienced severe outcomes less often, but $2.2 \%$ ( $n=15 / 672$ ) of cases within this age group were severe enough to require hospitalization. Based on available exposure information, $11.3 \%(n=59 / 520)$ of cases aged younger than 20 years had no known contact with a case. Canadian findings align with those of other countries.
\end{abstract}

This work is licensed under a Creative Commons Attribution 4.0 International License.

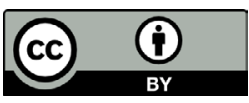

Affiliation

${ }^{1}$ Public Health Agency of Canada, Ottawa, ON

\section{*Correspondence: \\ lindsay.whitmore@canada.ca}

Editor's note: This article has been submitted as a Rapid Communication to provide current information related to COVID-19 that may have immediate implications.

Suggested citation: Paquette D, Bell C, Roy M, Whitmore L, Currie A, Archibald C, MacDonald D, Pennock J. Laboratory-confirmed COVID-19 in children and youth in Canada, January 15-April 27, 2020. Can Commun Dis Rep 2020;46(5):121-4. https://doi.org/10.14745/ccdr.v46i05a04

Keywords: COVID-19, youth, children, Canada, surveillance

\section{Introduction}

As of April 27, 2020, there were 47,327 COVID-19 cases reported in Canada. With the growth in new cases slowing, provincial, territorial and federal governments are planning how and when to ease some public health measures including the timing and parameters for reopening schools, daycares and other settings where children gather. To inform such decisions, it is important to understand the epidemiology of COVID-19 among children and youth in Canada.

\section{Current situation}

Data for this analysis were drawn from laboratory-confirmed cases reported to the Public Health Agency of Canada (PHAC) as of April 27, 2020. Of the 47,327 cases reported up to that date, detailed information was provided to PHAC for 26,876 cases. Of these, 24,723 were laboratory-confirmed and 24,079 included information on age. Among these cases, 3.9\% ( $n=938)$ were younger than 20 years of age, and form the basis for this analysis.
The rate of laboratory-confirmed COVID-19 cases was lower in individuals under 20 years of age at 11.9 per 100,000 (1), compared with 72.4 per 100,000 for those 20 to 59 years of age and 113.6 per 100,000 for those 60 years of age and older $(p<0.001)$. Rates per 100,000 population were consistent (7.111.4 per 100,000 ) across finer age groups for children younger than 15 years of age, while the 15-19 years of age group had a higher rate $(20.7$ per 100,000$)$ (see Table 1$)$. This difference may be due to adolescents being more independent than younger age groups and therefore more able to seek out social contact with peers (2). It is also important to note that observed

Table 1: Age distribution among cases younger than 20 years of age $(\mathrm{N}=938)$

\begin{tabular}{|c|c|c|c|}
\hline \multirow{2}{*}{$\begin{array}{l}\text { Age group } \\
\text { (years) }\end{array}$} & \multicolumn{2}{|c|}{ Frequency } & \multirow{2}{*}{$\begin{array}{l}\text { Rate per } \\
100,000\end{array}$} \\
\hline & $n$ & $\%$ & \\
\hline Younger than 1 & 42 & 4.5 & 11.4 \\
\hline $1-4$ & 109 & 11.6 & 7.1 \\
\hline $5-9$ & 152 & 16.2 & 7.5 \\
\hline $10-14$ & 215 & 22.9 & 11.2 \\
\hline $15-19$ & 420 & 44.8 & 20.7 \\
\hline Total & 938 & 100 & 11.9 \\
\hline
\end{tabular}


differences in rates across age groups may be due, in part, to differences in laboratory testing patterns by age.

Among the cases younger than 20 years, $50.7 \%$ were female and the median age was 13 years. The proportion of cases younger than 20 years reported daily remained fairly consistent over time on the days where cases numbered more than 100 (Figure 1), ranging from $2.1 \%$ to $6.9 \%$. Information on exposure category was available for $55.4 \%(n=520 / 938)$ of cases younger than 20 years for which PHAC received more detailed information. Of these, $20.4 \%$ were exposed internationally, $9.6 \%$ were contacts of travelers from affected areas, $58.7 \%$ were contacts of cases infected in Canada and $11.3 \%$ had no known contact with cases. The younger age groups ( 0 to 4,5 to 9 and 10 to 14 years) had a lower percentage of cases with no known contact with a case (8.0\%, 8.3\% and $9.7 \%$, respectively) compared with the 15-19 year age group, in which $15.1 \%$ of cases had no known contact.

Figure 1: Epidemiologic curve from January 15 to April 27 , by age group ${ }^{a},(N=22,973)$

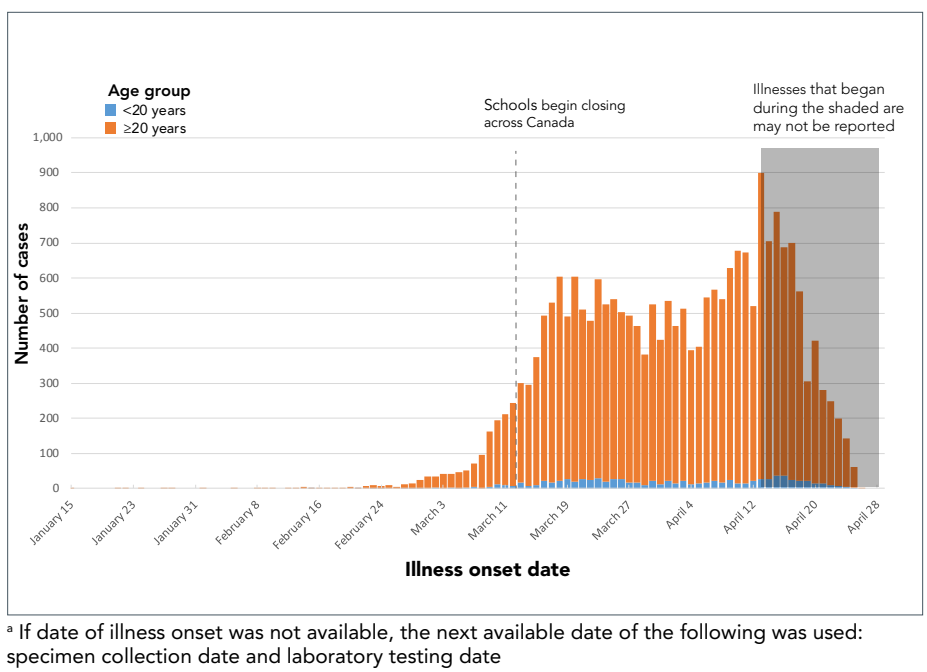

The distribution of cases in the younger than 20 years age category varied significantly across provinces and territories $(p<0.001)$ (see Table 2), which may reflect differences in the local epidemiology of COVID-19 across provinces and territories and/ or differences in laboratory testing criteria across jurisdictions. Among the jurisdictions that reported more than 100 cases (this excludes Yukon, Northwest Territories, Nunavut and Prince Edward Island), in British Columbia, Saskatchewan, Manitoba and Ontario, $5.0 \%$ or less of all reported cases were younger than 20 years, while Alberta, Quebec, New Brunswick, Nova Scotia and Newfoundland and Labrador reported a higher proportion of cases in this age group (between $6.8 \%$ and $11.1 \%$ ). At the time of this report, no outbreaks were noted in settings where children gather (e.g. daycares, schools, camps, etc.). This may be due to the early timing of schools and some daycare closures.

Information on whether cases were symptomatic or not was available for $24.7 \%(n=5,939 / 24,079)$ of cases for which PHAC
Table 2: Number and proportion of cases younger than 20 years of age, for provinces with more than 100 cases reported $(\mathrm{N}=937)$

\begin{tabular}{|c|c|c|}
\hline \multirow{2}{*}{ Province $^{a}$} & \multicolumn{2}{|c|}{ Number and proportion of cases } \\
\hline & $\mathbf{n}$ & $\%$ \\
\hline Ontario & 328 & 2.2 \\
\hline Alberta & 229 & 8.1 \\
\hline Quebec & 226 & 7.3 \\
\hline Nova Scotia & 85 & 9.8 \\
\hline $\begin{array}{l}\text { British } \\
\text { Columbia }\end{array}$ & 25 & 1.6 \\
\hline $\begin{array}{l}\text { Newfoundland } \\
\text { and Labrador }\end{array}$ & 22 & 8.6 \\
\hline Manitoba & 10 & 4.0 \\
\hline New Brunswick & 8 & 6.8 \\
\hline Saskatchewan & 4 & 3.2 \\
\hline
\end{tabular}

fewer than 100 cases for all ages for this time period

received detailed reports. A larger proportion of asymptomatic cases $(10.7 \%)$ was noted in the younger than 20 years age group, compared with $2.4 \%$ in those aged $20-59$ years and $4.1 \%$ in those aged 60 and older. These proportions are likely underestimates of asymptomatic cases across all age groups, given that, during the time period in question, testing was focused on high risk populations who were symptomatic.

Symptom information was available for $24.6 \%(n=5,912 / 24,079)$ of cases for which PHAC received detailed information. Of those who experienced symptoms, the three most common symptoms differed across age groups. The three most common symptoms for those younger than 20 years of age were cough $(57.0 \%)$, runny nose $(41.2 \%)$ and headache (39.4\%); compared with cough (74.2\%), headache (64.3\%) and pain (56.0\%) for those aged $20-59$ years and cough $(75.1 \%)$, weakness $(56.2 \%)$ and fever (51.9\%) for those aged 60 and older. Other common symptoms in those younger than 20 years of age included fever (36.4\%), sore throat (34.3\%), weakness (31.8\%) and chills (30.6\%).

Severe outcomes were less likely to occur in the younger age group. Hospitalization status was available for $57.0 \%$ of all cases $(n=13,723 / 24,079)$ for which PHAC received detailed information. Among individuals younger than 20 years of age, $2.2 \%$ were hospitalized, compared with $10.4 \%$ in those aged 20-59 years and $35.6 \%$ among those aged 60 and older. Among those hospitalized, in cases younger than 20 years of age, $13.3 \%$ were admitted to the Intensive Care Unit. Across all age groups, these proportions likely overestimate the true proportion of COVID-19 infections that result in severe outcomes, as individuals who experienced more severe symptoms and outcomes may have been more likely to be tested and reported than those who were asymptomatic or had only mild symptoms.

Among those younger than 20 years of age, hospitalization information was available for $71.6 \%(n=672 / 938)$ of cases. There 
were only 15 hospitalizations in this age group, among which infants younger than one year of age had a higher proportion of hospitalizations than other age groups (see Table 3). However, the numbers were small in this age group, and these results should be interpreted with caution. Within the 15 hospital admissions in cases younger than 20 years of age, two cases were admitted to the Intensive Care Unit, and both cases were younger than one year of age. No deaths were reported in individuals younger than 20 years of age as of the date of this report, based on public reporting by province and territory health officials.

Table 3: Hospitalization status for cases younger than 20 years of age $(\mathrm{N}=672)$

\begin{tabular}{|l|r|r|r|r|}
\hline \multirow{2}{*}{$\begin{array}{c}\text { Age } \\
\text { group } \\
\text { (years) }\end{array}$} & \multicolumn{2}{|c|}{ Hospitalized } & \multicolumn{2}{c|}{ Not hospitalized } \\
\cline { 2 - 5 } $\begin{array}{l}\text { Younger } \\
\text { than 1 }\end{array}$ & $\mathbf{n}$ & 13.3 & 26 & 86.7 \\
\hline $1-4$ & 0 & 0 & 83 & 100 \\
\hline $5-9$ & 0 & 0 & 118 & 100 \\
\hline $10-14$ & 2 & 1.3 & 153 & 98.7 \\
\hline $15-19$ & 9 & 3.1 & 277 & 96.9 \\
\hline Total & 15 & 2.2 & 657 & 97.8 \\
\hline
\end{tabular}

\section{Conclusion}

The data presented in this report add to our knowledge of the epidemiology of COVID-19 among children and youth. Few reports have been published to date, but based on what is available in the published literature and from surveillance reports, the Canadian findings are in line with those from other countries. Fewer cases have been reported among children and youth, compared with older age groups (3-5). A higher proportion of children and youth were asymptomatic, and they experienced different symptoms than adults (6-8). While less severely affected (3-5), hospitalizations still occurred, including among infants $(7,9)$ and, as in the United States, a larger proportion of infants were hospitalized when compared with older children and youth (8).

Based on these and other findings, a significant proportion of cases among children and youth was asymptomatic. Though preliminary studies suggest children are less important sources of SARS-CoV-2 infection than adults, asymptomatic transmission has been noted (10). It will, therefore, be important to maintain key public health measures even as some controls are relaxed. Among these, behaviours such as staying home when ill, maintaining physical distancing, use of non-medical masks and frequent handwashing should continue to be encouraged in this age group to prevent transmission. As well, since higher rates of confirmed infection were observed in those aged 15-19 years, additional efforts to educate and reinforce public health preventative measures, such as physical distancing, may be needed to target this more independent and mobile age group.
To ensure that COVID-19 continues to be monitored in children and youth, plans are underway for enhanced surveillance of the pediatric population. Data will be available through multiple data streams in addition to province and territory case-based reporting. Enhanced surveillance will make use of existing administrative databases and surveillance systems, including the Canadian Institute for Health Information's Discharge Abstract Database, the Canadian Nosocomial Infections Surveillance Program and the Canadian Pediatric Surveillance Program. These data streams will provide complimentary information to monitor trends in severe pediatric cases, identify risk factors associated with disease, and assess the burden of disease within this population.

\section{Authors' statement}

DP - Conceptualization, original draft, review and editing CB - Data curation, formal analysis, review and editing MR - Data curation, formal analysis

LW - Review and editing AC - Review and editing CA - Review and editing DM - Review and editing JP - Review and editing

\section{Conflict of interest}

None.

\section{Acknowledgements}

Authors wish to thank provincial and territorial surveillance partners; national and provincial laboratory partners; and the Health Portfolio Operations Centre's Surveillance Team, Public Health Agency of Canada.

\section{Funding}

This work was supported by Public Health Agency of Canada.

\section{References}

1. Statistics Canada. Census Profile, 2016 Census. Statistics Canada Catalogue no. 98-316-X2016001. Ottawa (ON): Stats Can; released February 8, 2017; updated June 18, 2019. https://www12.statcan.gc.ca/census-recensement/2016/dp$\mathrm{pd} /$ prof/index.cfm? Lang $=\mathrm{E}$

2. Oosterhoff B, Palmer C. Psychological Correlates of News Monitoring, Social Distancing, Disinfecting, and Hoarding Behaviors Among US Adolescents During the COVID-19 Pandemic. PsyArXiv; March 23, 2020. DOI 
3. Public Health England: Weekly Coronavirus Disease 2019 (COVID-19) Surveillance Report. Year: 2020; Week: 17

(Accessed 2020-04-29). https://assets.publishing.service.gov. uk/government/uploads/system/uploads/attachment_data/ file/880925/COVID19_Epidemiological_Summary_w17.pdf

4. World Health Organization (Regional Office for Europe). COVID-19 weekly surveillance report. Data for the week of 13-19 April 2020 (Epi week 16). WHO; 2020 (Accessed 202004-29). http://www.euro.who.int/en/health-topics/healthemergencies/coronavirus-covid-19/weekly-surveillance-report

5. Australian Government Department of Health. Coronavirus (COVID-19) current situation and case numbers.

Canberra (Australia): DOH; 2020 (Accessed 2020-04-

29). https://www.health.gov.au/news/health-alerts/

novel-coronavirus-2019-ncov-health-alert/coronavirus-covid19-current-situation-and-case-numbers

6. Qiu H, Wu J, Hong L, Luo Y, Song Q, Chen D. Clinical and epidemiological features of 36 children with coronavirus disease 2019 (COVID-19) in Zhejiang, China: an observational cohort study. Lancet Infect Dis 2020 Mar;25(Ma rch):S1473-3099(20)30198-5. DOI PubMed
7. Hong H, Wang Y, Chung HT, Chen CJ. Clinical characteristics of novel coronavirus disease 2019 (COVID-19) in newborns, infants and children. Pediatr Neonatol 2020 Apr;61(2):131-2. DOl PubMed

8. Coronavirus Disease 2019 in Children — United States, February 12-April 2, 2020. Morb Mortal Wkly Rep MMWR. 2020;69(14):422-6. DOI

9. Dong Y, Mo X, Hu Y, Qi X, Jiang F, Jiang Z, Tong S. Epidemiology of COVID-19 Among Children in China. Pediatrics 2020 Mar;145(4):e20200702. [Epub ahead of print]. DOI PubMed

10. Hu Z, Song C, Xu C, Jin G, Chen Y, Xu X, Ma H, Chen W, Lin $Y$, Zheng $Y$, Wang J, Hu Z, Yi Y, Shen $\mathrm{H}$. Clinical characteristics of 24 asymptomatic infections with COVID-19 screened among close contacts in Nanjing, China. Sci China Life Sci 2020 May;63(5):706-11. DOI PubMed

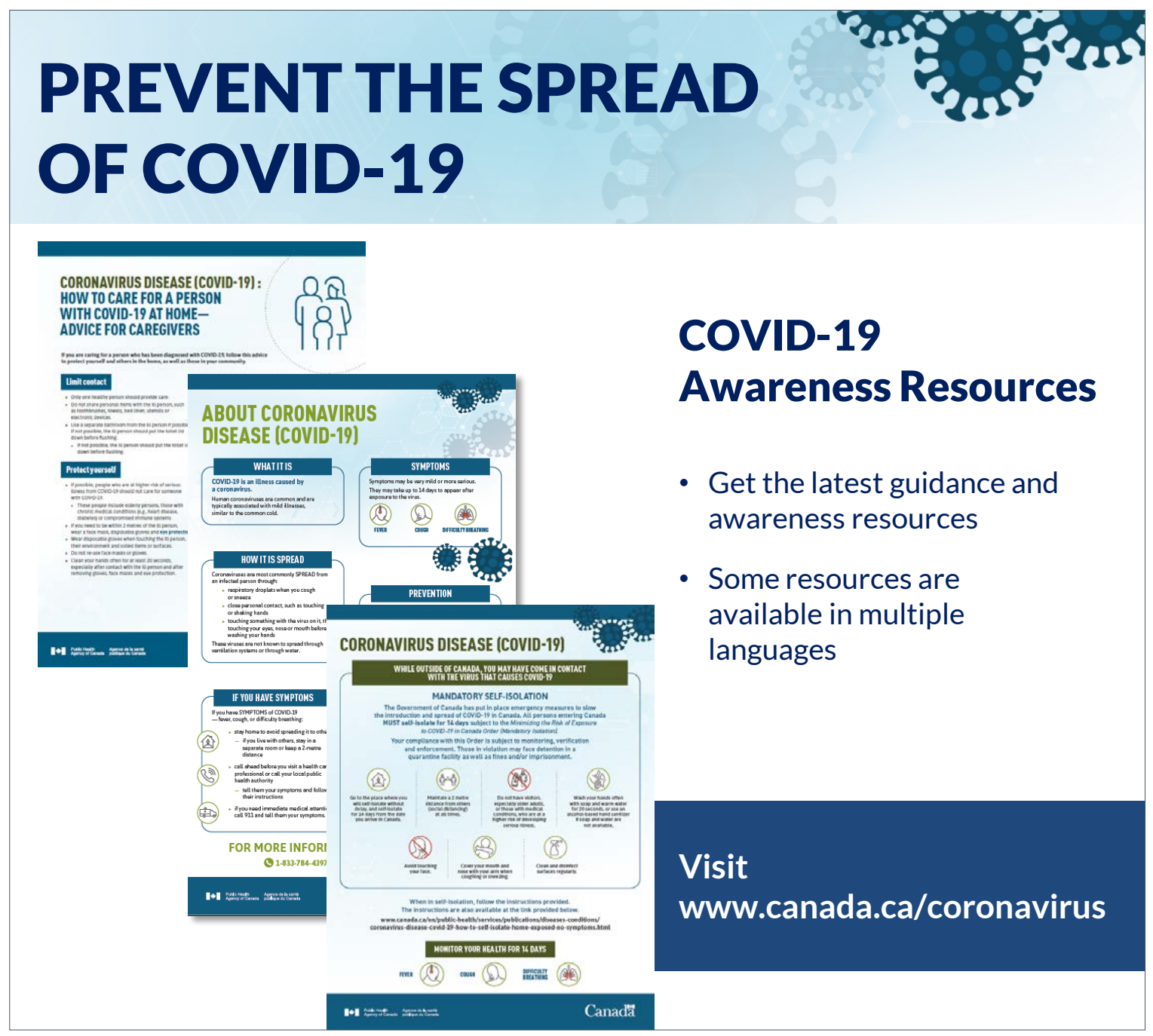

